\title{
A New Parental Mentalization Focused Ultrasound Intervention for Substance Using Pregnant Women. Effect on Self-reported Prenatal Mental Health, Attachment and Mentalization in a Randomized and Controlled Trial
}

\author{
Heidi Jussila ${ }^{1,2}$ (D) Eeva Ekholm ${ }^{3,4} \cdot$ Marjukka Pajulo $^{5}$ \\ Published online: 13 January 2020 \\ (C) The Author(s) 2020
}

\begin{abstract}
The effect of a novel mentalization-based parenting intervention was explored on prenatal self-reported mentalization (P-PRFQ), attachment (MFAS), depression (EPDS) and anxiety (STAI) among women with substance use problems. The participants were 90 pregnant women referred to obstetric outpatient care due to recent or current substance use and randomized into intervention $(n=46)$ and control $(n=44)$ groups. The intervention group received three interactive $4 \mathrm{D}$ ultrasound sessions and a week-by-week pregnancy diary. The control condition was constituted of treatment-as-usual in obstetric care. Unfortunately, the efficacy of the intervention on maternal prenatal mental health, attachment, and parental mentalization was not substantiated. The negative results may be related to the small sample size, the patient-reported outcomes, or insufficient efficacy within this high-risk group. In the context of high psychosocial risks and follow-up by Child Welfare Services, the patient-reported outcomes may have underestimated prenatal adversity. The role of the research context, methodology, and possible sources of bias in the outcome assessment are discussed.

The trial registration number in the ClinicalTrials.gov: NCT03413631
\end{abstract}

Keywords Pregnancy Prenatal · Substance use disorder Prenatal parenting · Prenatal depression · Prenatal anxiety

Heidi Jussila

hemhaan@utu.fi

Eeva Ekholm

eeva.ekholm@fimnet.fi

Marjukka Pajulo

marjukka.pajulo@utu.fi

Extended author information available on the last page of the article 
Substance use in pregnancy constitutes a significant public health issue as it has been considered as one of the key determinants of the intergenerational transmission of healthrelated inequality (Aizer and Currie 2014; Forray et al. 2014; Behnke and Smith 2013; Roozen et al. 2016). Previous research has established that the child exposed prenatally to substances is at risk for preterm birth, low birth weight, insecure attachment, and long-term difficulties in emotional, social, behavioral, physical, and cognitive development and growth (Behnke and Smith 2013; Stein et al. 2014; Forray and Foster 2015; Parolin and Simonelli 2016). In a recent survey, around $9 \%$ of pregnant women self-reported alcohol use and over 5\% illicit drug use in the USA (Substance Abuse and Mental Health Services Administration 2014). The use of prescription opioids has escalated among fertile-aged and pregnant women in many countries (Desai et al. 2015; Patrick et al. 2015; Ollgren et al. 2014). In Finland, the number of problem drug users has unfortunately increased, and the proportion of fertile-aged women among them (Ollgren et al. 2014). Despite this knowledge, the number of psychosocial interventions specifically designed for pregnant women with substance use disorders is surprisingly low (Stein et al. 2014; Forray and Foster 2015; Howard et al. 2014; Terplan et al. 2015a).

Substance use in pregnancy has been found to indicate cumulative adversity. Indeed, substance use while pregnant has been associated with a high level of prenatal stress (Woods et al. 2010) and the prevalence of maternal perinatal mental disorders (Holbrook and Kaltenbach 2012; Strengell et al. 2014). The prevalence of prenatal depression has been reported to be around 40-50\% among substance using women (Holbrook and Kaltenbach 2012; Ordean et al. 2013; Pajulo et al. 2011a) which is high compared to an approximate prevalence of $10 \%$ in a normal population of pregnant women (Gavin et al. 2005). Unfortunately, the comorbidity of substance use disorders and prenatal stress adversely affects maternal and fetal health through multiple divergent pathways. First, maternal perinatal mental disorders have a wide spectrum of independent adverse effects on the developing fetus (Stein et al. 2014; Waters et al. 2014). Second, prenatal stress and depression have been found to predict unfavorable health practices (Alhusen et al. 2016; Cannella et al. 2018) and a higher risk of substance use in pregnancy (Alhusen et al. 2016; Hyer et al. 2019; Shmulewitz and Hasin 2019). Generally, stress associates with increased craving, and potentially with opioid use, among persons with an opioid use disorder (MacLean et al. 2019). Recent evidence has established that a high level of prenatal stress increases consumption of alcohol and marijuana during pregnancy (Hyer et al. 2019). In addition, an increased risk of binge drinking has been observed among pregnant women with depression (Shmulewitz and Hasin 2019). Third, substance use in pregnancy and a high level of prenatal stress may have an additive deteriorating effect on child outcomes (Zhao et al. 2017) and resilience-building factors, such as preand postnatal parenting (Rutherford and Mayes 2019). A recent population-based cohort study has revealed that the interaction effect of substance use in pregnancy and maternal mental disorder predicts an increased risk of low birth weight in newborns; the poorest neonatal outcome observed was among pregnant women with poly or illicit drug use and a comorbid mental disorder (Zhao et al. 2017).

Extensive research has shown that nurturing care, especially by parents, is the most important factor promoting child development (Britto et al. 2017). Parenting and maternal mental health have been especially found to be modifiable factors promoting the resilience of children in adversity (Traub and Boynton Jarrett 2017). The existing body of research suggests that parenting begins in pregnancy (Glover and Capron 2017). It is noteworthy that becoming a caregiver often means increased motivation and a unique chance for recovery from substance use disorders (Jessup et al. 2014). Importantly, stronger prenatal parenting has been found to 
be the most powerful predictor of favorable health practices in pregnancy (Cannella et al. 2018) and to protect pregnant women from prenatal stress/depressive symptoms in late pregnancy and the postpartum period (Goecke et al. 2012). Further, high-quality nurturing care has been found to mitigate the harmful effects of prenatal exposure to substances (Bada et al. 2012) and to promote developmental trajectories in children whose families are affected by parental substance use (Wlodarczyk et al. 2017). Parenting has also been considered to be the key modifiable pathway mediating the effects of maternal perinatal mental health problems on child development (Stein et al. 2014).

Unfortunately, previous studies concerning mothers with substance use disorders have shown that their transition to parenthood (Shieh and Kravitz 2002; Shieh and Kravitz 2006), parental reflective functioning (Pajulo et al. 2008; Pajulo et al. 2012; Suchman et al. 2010; Suchman et al. 2017), early interaction with the infant and, abilities to provide nurturing care and promote secure attachment are often impaired (Rutherford and Mayes 2019; Suchman et al. 2018; Suchman et al. 2011; Rutherford and Mayes 2017). There is a growing body of research suggesting that parenting interventions should start before birth, especially for pregnant women with known vulnerabilities (Glover and Capron 2017). Maternal-fetal attachment and the expectant mother's thoughts and feelings towards the unborn child have been found to predict mother-child interaction quality (Foley 2018). Parental mentalization refers to a parent's curiosity about and interest in fetal development and the emerging personality of the child (Pajulo et al. 2015; Slade 2005). A parent with a prenatal capacity to mentalize the child is able and willing to think of her/his own feelings and experience, the baby's experience and perspective, the impact of her/his own mental states and behavior on the fetus-baby, and to imagine experiences in future situations with the child (Slade et al. 2007). Better mentalizing in general has been found to predict stronger prenatal attachment and a lower level of psychological symptoms in expecting parents (Berthelot et al. 2019). Notably, higher parental mentalizing has been found to promote resilience-building parenting as it enables the mother to respond with greater caregiving sensitivity to the infant's needs and contributes to the child attachment security (Camoirano 2017); this has also been found to be true among parenting women with substance use problems (Suchman et al. 2018). Therefore, parental mentalization offers an excellent focus for early interventions. Maternal-fetal attachment refers to the pregnant woman's emotional connectedness with the fetus which is displayed in thoughts, attitudes, feelings, and interactive behavior towards the fetus (Cannella 2005; Cranley 1981). Stronger prenatal attachment has been considered influential, as it has predicted abstaining from substance use and smoking during pregnancy (Magee et al. 2014; Massey et al. 2015; Sedgmen et al. 2006), stronger postnatal bonding with the newborn (Dubber et al. 2015), better quality of early mother-baby interaction (Siddiqui and Hagglof 2000), child secure attachment (Huth Bocks et al. 2004), and healthy child development (Alhusen et al. 2013). From an intervention point of view, ultrasound screening and consultation have been shown to associate with stronger prenatal attachment (Sedgmen et al. 2006; Yarcheski et al. 2009; Boukydis et al. 2006; Borg Cunen et al. 2017) and fetal ultrasound is now considered to be the most promising intervention method to enhance maternal-fetal attachment (Borg Cunen et al. 2017). Although 2D and 3D/4D ultrasound imaging have been found equally effective means to improve prenatal attachment, 4D ultrasound technology offers better visualization of the fetus and thus may contribute to more positive and intensive maternal-fetal attachment (de Jong-Pleij et al. 2013).

A tendency towards co-occurrence of maternal substance use disorders, prenatal stress, and problems in the transition to parenthood is very likely to constitute an accumulative burden for maternal and child health. There is an urgent need for early interventions that would concurrently contribute to health practices, mental health and parenting of pregnant women with substance use 
disorders. A new mentalization-based parenting intervention utilizing interactive fourdimensional (4D) ultrasound imaging and a new pregnancy diary was designed for the prenatal care of women with a recent or current substance use problem (Pajulo et al. 2016). The aim of the current study was to explore the efficacy of the intervention on prenatal parenting, i.e., maternalfetal attachment and parental mentalization, and maternal mental health in a randomized controlled trial (RCT). We hypothesized that the intervention group would demonstrate (1) stronger maternal-fetal attachment and prenatal parental mentalization post-intervention and (2) a greater improvement in prenatal attachment and mentalization than the control group. In addition, we presumed the intervention group would display (3) a lower level of prenatal depressive and anxiety symptoms post-intervention, and (4) a greater decline in depressive symptoms and anxiety symptoms during pregnancy when compared to the control group.

\section{Method}

\section{Participants}

The study was carried out at the obstetric outpatient clinic organized for women with substance use disorders, at Turku University Hospital in Finland. The participants were 90 pregnant women who had been referred from primary health care to this tertiary obstetric outpatient clinic because of (1) identified or self-reported alcohol abuse, illicit drug use, or misuse of a prescription medication within 3 years prior or during this pregnancy or (2) a sum score of $\geq 3$ points in the TWEAK alcohol consumption screen (Russell 1994). The inclusion criteria for the study were a singleton pregnancy $<22$ gestational weeks (gwks) at referral. In Finland, the coverage of prenatal screening can be considered excellent as nearly $100 \%$ of pregnant women use public and cost-free antenatal care (Webpages of National Institute for Health and Welfare in Finland 2015).

Of all the eligible women during the data collection period between October 2011 and November $2014(n=126), 75 \%(n=95)$ agreed to participate and gave their informed consent. The participants were randomized into the intervention $(n=47)$ and control group $(n=48)$. After randomization, five participants were excluded due to pregnancy-related reasons such as twin pregnancy, miscarriage, and induced abortion. The exclusion concerned one woman in the intervention group and four women in the control group. The study protocol is presented in Table 1.

Descriptive characteristics of the whole sample $(N=90)$ are presented in Table 2 . The median age of the participants was 24 years (range 17-40). The socioeconomic status of the participants was low or even marginal, and $41 \%$ of the women had criminality in their background. One third of the pregnant women were living alone and in two third of the cases the child's father also had a substance use problem. Over $70 \%$ of the pregnancies were unintended. The median length of participants' substance use history was 4 years (range 0-28). A majority $(81 \%)$ of the women reported recent or current use of illicit drugs, and $49 \%$ of the participants had used both drugs and alcohol. Nearly one half of the women had a history of intravenous drug use. Prenatal clinical assessments and maternal documented self-reports showed a similar degree of maternal substance use in both groups during pregnancy. Within the whole sample, $56 \%$ of the pregnant women had used alcohol or drugs before their positive pregnancy test and 33\% after being aware of pregnancy. Almost $80 \%$ of the participants suffered from psychiatric comorbidity, and $60 \%$ of the women reported suicidal ideation or attempts in their past. About one third (28\%) of the participants reported somatic comorbidities, most commonly respiratory, neurological, musculoskeletal, or thyroid illnesses, and $27 \%$ were seropositive for hepatitis $\mathrm{C}$. The sample characteristics did not reveal any 


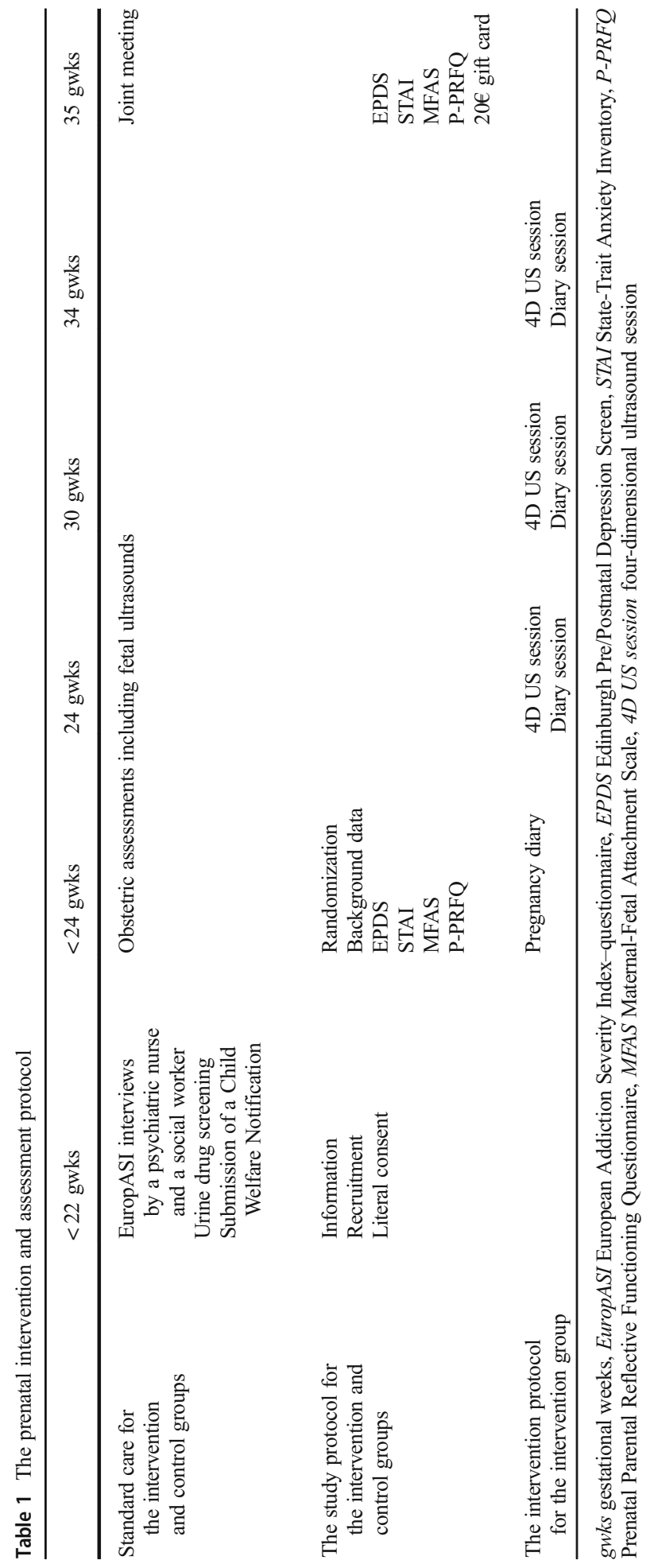




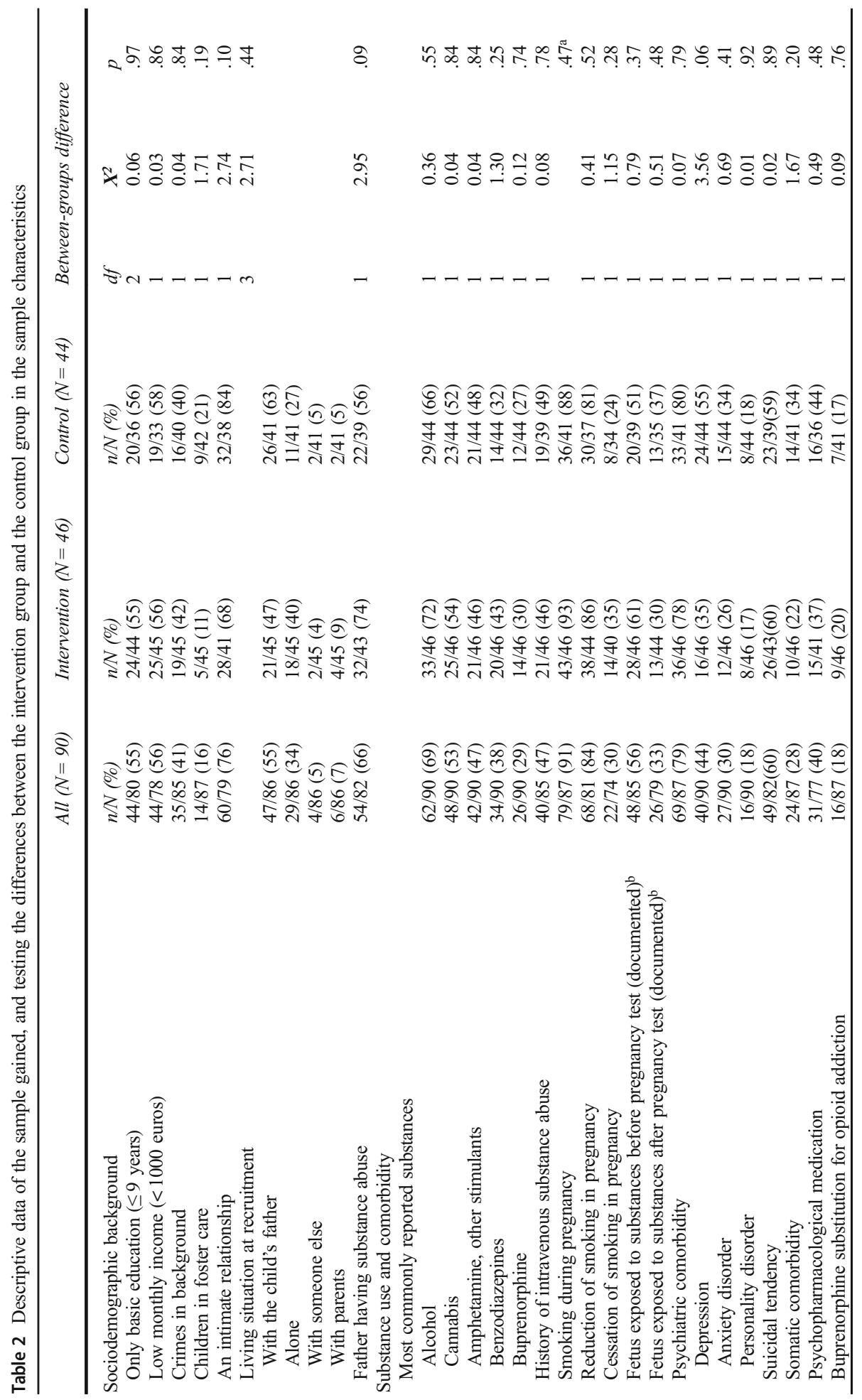




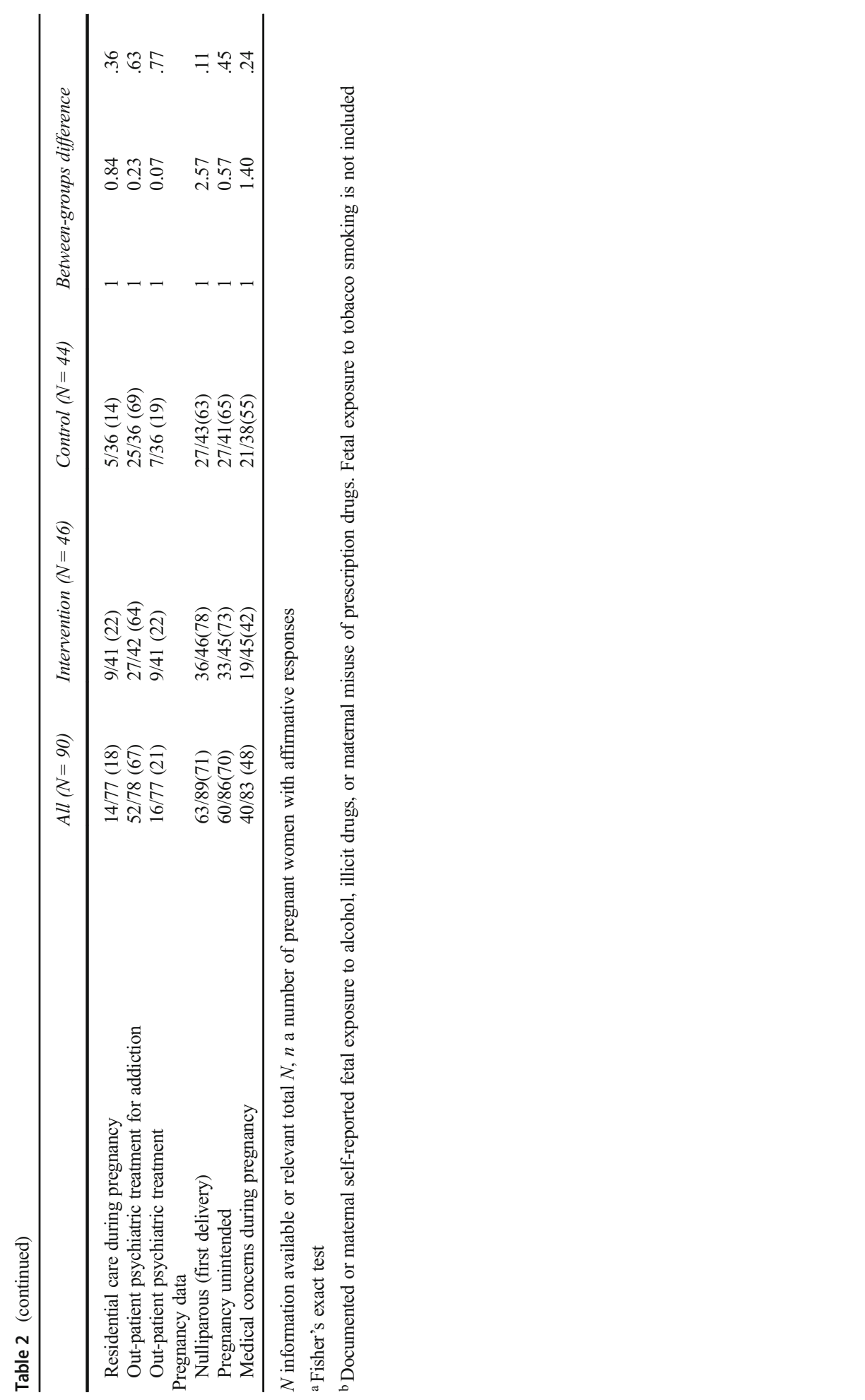


differences between the intervention and the control group at baseline, which indicated a successful randomization procedure.

\section{Procedure}

Research Design The research protocol was implemented in the clinical practice at the hospital obstetric outpatient clinic (Table 1). A psychiatric nurse offered all the eligible pregnant women an opportunity to participate. A written informed consent was obtained. The patients were randomized into the intervention and control groups using a computergenerated randomization in blocks of four, with separate blocks for the women on opioid maintenance treatment. In the post-intervention phase at 35 gwks, all participants were compensated with a 20 euros gift card targeted to the child's needs.

All participants received treatment as usual at the obstetric outpatient clinic. The treatment as usual for pregnant women with substance use disorders included prenatal screening, clinical obstetric examinations, fetal assessment with obstetric ultrasound, and treatment of concomitant somatic diseases and pregnancy complications. A multidisciplinary team, consisting of an obstetrician, a midwife, a social worker, and a psychiatric nurse, assessed the somatic health and psychosocial situation of the mother/family. Substance use was screened with urine samples, and mental health and social problems with interviews based on the European Addiction Severity Index-questionnaire (EuropASI) (Kokkevi and Hartgers 1995). The pregnant women were referred to addiction treatment, social services, or psychiatric care when needed. The Child Welfare authorities were informed in case where maternal prenatal substance use was recognized, and a joint meeting with them was routinely scheduled for the third trimester.

Description of the Intervention Based on the theoretical rationale described in the introduction, two main intervention elements were chosen to enhance prenatal parental mentalization and maternal-fetal attachment in this study: interactive 4D ultrasound imaging and a new mentalization-focused pregnancy diary designed for this study (Table 1). The method has been previously described in detail in a separate article (Pajulo et al. 2016).

Interactive Use of Ultrasound Imaging Three interactive 4D ultrasound sessions were offered for the intervention group at 24, 30, and 34 gwks. The mothers participated in the sessions alone, but the father of the baby or the mother's close companion was invited to look at the baby together with the mother, after the session. The sessions lasted approximately $30 \mathrm{~min}$ and were performed by an experienced obstetrician and an infant mental health professional working in collaboration. The interactive 4D ultrasound sessions were built on a previous method called "ultrasound consultation", where the idea is to observe the fetus together with the parent(s); the fetal features, position, sleep-awake rhythm, personal characteristics, activities in the uterus, and responses to mother's initiatives for interaction (Boukydis and Stockman 2012; Boukydis 2006). During the sessions, the pregnant woman was encouraged to explore her thoughts, experiences, and emotions related to watching the fetus on the screen. The aim was to evoke the mother's active interest in this particular child and his/her individual perspective, to enhance parental mentalization and maternal-fetal attachment, and hence to support the mother's emerging parenthood (see Pajulo et al. 2016).

The Pregnancy Diary To also keep the child more actively in the mother's mind between the ultrasound sessions, a mentalization-focused pregnancy diary was designed and given to the 
women in the intervention group. Three prenatal meetings with the infant mental health professional were offered to give an opportunity for the mother to go through her experiences and possible questions that arose while using the diary. The diary meetings were arranged within 2 weeks after each ultrasound session. For each pregnancy week, the diary contained short sections of up-to-date information about the pregnancy phase, fetal development, and health-promoting practices. The key elements were the mentalization-focused questions and tasks inspiring the pregnant woman to think of her experiences of this pregnancy and becoming a parent, to observe the fetus more carefully, and to consider situations from the child's perspective (Pajulo et al. 2011b).

Collection of the Data The data was collected using standardized questionnaires, questionnaires constructed for the study, and from electronic medical records. The psychiatric nurse and the social worker interviewed the participants as part of the routine clinical practice. The interviews were based on the European Addiction Severity Indexquestionnaire (EuropASI) in which items were considered regarding previous and current maternal physical and mental health, substance use, employment and income, legal status and close relationships (Kokkevi and Hartgers 1995). Socio-demographic data was obtained with a ten-item questionnaire at baseline. Information regarding fetal exposure to substances was based on the pregnant woman's self-reporting and clinical documentation (intoxications, urine screening results, marks indicating intravenous substance use). The data on substance use and psychiatric diagnosis and/or history was based on the EuropASI interview and medical records. The standardized self-report measures for assessment of outcomes, maternal depressive and anxiety symptoms, maternal-fetal attachment, and prenatal parental mentalization were administered by the social worker during pregnancy at two time points: before and after the intervention $(<24$ th and $>34$ th gestational weeks, respectively) (Table 1).

Ethics All procedures followed were in accordance with the ethical standards of the responsible committee on human experimentation and with the Helsinki Declaration of 1964, and its later amendments. The study was approved by the Joint Ethics Committee of the University of Turku and The Hospital District of Southwest Finland on 14th of June 2011. The trial was registered retrospectively in the ClinicalTrials.gov (the reference number: NCT03413631). Informed consent was obtained from all individual participants included in the study.

\section{Measures}

Edinburgh (Pre-) Postnatal Depression Scale Depressive symptoms were assessed with the Edinburgh (Pre-) Postnatal Depression Scale (EPDS). It is a self-report instrument containing 10 items scored on a four-point scale (0 to 3), with a total sum score ranging from 0 to 30. A higher sum score indicates a higher amount of depressive symptoms (Cox et al. 1987). In antenatal use the sensitivity and specificity of the EPDS measure have varied between 64 and 100\% and 73-100\%, respectively (Kozinszky and Dudas 2015). EPDS sum cut off score $\geq 13$ has been reported to be optimal in detecting prenatal depression, with a sensitivity of $77 \%$ and specificity of $94 \%$ (Rubertsson et al. 2011), and was used in this study. In the current sample, the internal consistency for the EPDS 
was Cronbach's $\alpha=0.87$ at the first time point and Cronbach's $\alpha=0.88$ at the second time point.

State-Trait Anxiety Inventory Anxiety symptoms were assessed with the state section of the State-Trait Anxiety Inventory (STAI). It is a self-report measure containing 20 items scored on a four-point scale (1-4), with the sum score ranging from 20 to 80 . A higher sum score indicates a higher amount of anxiety symptoms (Spielberger et al. 1970). The STAI has also been reported valid for antenatal use (Grant et al. 2008). In this sample, the reliability of the STAI measure was Cronbach's $\alpha=0.93$ at both time points.

Maternal-Fetal Attachment Scale The Maternal-Fetal Attachment Scale (MFAS) is a 24item self-report questionnaire for assessment of behavioral aspects of maternal emotional connectedness with the fetus. It is designed for use in the 2 nd and 3 rd trimester. The items are scored on a five-point scale (1-5) with a total score ranging hence from 24 to 120, a higher sum score indicating a stronger attachment to the fetus. It contains five subscales: "Role taking", "Differentiation of self from fetus", "Interacting with the fetus", "Attributing characteristics to the fetus" and "Giving of self" (Cranley 1981). In the current study, 7 items were selected as already being appropriate for use in an earlier phase of pregnancy (the items 2, 5, 8, 11, 14, 18, 23 from the original long 24item version of MFAS). The total 24-item measure was used to assess late pregnancy maternal-fetal attachment. In the current sample, the reliability of the shorter MFAS version was Cronbach's $\alpha=0.72$, and of the full version: Cronbach's $\alpha=0.83$ and its factors, "Role taking": Cronbach's $\alpha=0.76$, "Differentiation of self from fetus": Cronbach's $\alpha=0.39$, "Interacting with the fetus": Cronbach's $\alpha=0.65$, "Attributing characteristics to the fetus": Cronbach's $\alpha=0.56$ and "Giving of self": Cronbach's $\alpha=$ 0.57 .

Prenatal Parental Reflective Functioning Questionnaire Prenatal Parental Reflective Functioning Questionnaire (P-PRFQ) was used to assess prenatal maternal mentalization (Pajulo et al. 2015). It is designed for use in the 2nd and 3rd trimester. In the current study, 8 items were selected as already being appropriate for use in an earlier phase of pregnancy. This short version was administered to the participants at baseline. At the beginning of the study, 18 participants also responded to this this short version of the measure at the post-intervention time point. However, the final construct-validated 14item version of P-PRFQ became available during our data collection phase and was administered to the rest of the sample $(n=51)$ post-intervention. Three factors were found in the original population-based study, these were named "Opacity of mental states", "Reflecting on the fetus-baby", and "Dynamic nature of mental states" (Pajulo et al. 2015). The pregnant women responded to the items using a scale from 1 to 7 (from "strongly disagree" to "strongly agree"). The questionnaire includes three types of items: the optimal answer at the high end, low end or in the middle of the scale (Luyten et al. 2009). After recoding, the higher scores indicate higher mentalization; the factor and total index scores ranging theoretically from 1 to 7 . The reliability of the P-PRFQ was Cronbach's $\alpha=0.70$ for the early pregnancy 8-item version, and Cronbach's $\alpha=0.57$ for the 14-item version and for its factors; "Opacity of mental states": Cronbach's $\alpha=0.71$, "Reflecting on the fetus-baby": Cronbach's $\alpha=0.48$, and "Dynamic nature of mental states": Cronbach's $\alpha=0.50$. 


\section{Statistical Analyses}

A priori statistical power analysis was performed for sample size estimation. The power analysis and sample size estimation were calculated with regard to the primary outcome of the study, prenatal depressive symptoms (EPDS), and the parameter estimates for the sample size calculation were approximated based on previous studies. The study was designed to detect a meaningful difference of 3 points in the EPDS measure corresponding to approximately a medium effect size using Cohen's criteria (Cohen 1988). With an alpha $=.05$ and power $=0.80$, the projected sample size required for this effect size was approximately $N=80$ $(40+40)$ for the between-group comparison with a $t$ test.

In the descriptive background data, comparisons between the intervention and control groups in nominal variables were done using a Chi-square test or a Fisher's exact test, when appropriate. Comparisons between the two groups in non-normally distributed continuous variables were done using a Kruskal-Wallis test.

An intention-to-treat analysis method was used for analyzing the results. The participants were included in the statistical analysis according to the group they were originally assigned, regardless of their attendance at the intervention sessions. In the questionnaire data, sporadic missing values were replaced by the mean index item value of each respondent, otherwise only completed assessments were included in the analyses. As the questionnaire data were normally distributed, a two-tailed independent sample's $t$ test was used to analyze the difference between the intervention and the control group in the questionnaire scores. In addition, effect sizes (Cohen's $d$ ) were calculated (Cohen 1988). The reported Cohen's $d$ values are positive if the mean difference was in the hypothesized direction with an interpretation of 0.2 referring to small, 0.5 to medium and 0.8 to a large effect size (Cohen 1988). Analysis of covariance (ANCOVA) was performed to test the difference between the groups in the change of the questionnaire scores. Equivalence of the variances was confirmed, and significant group differences were not found.

The Bayes factors (BF) were calculated using the function $\operatorname{lmBF}$ in the BayesFactor $\mathrm{R}$ package (Morey et al. 2018). The null hypothesis was that the intervention has zero effect. The prior distribution for the intervention effect (measured in standard deviations of the response variable) under the alternative hypothesis was a Cauchy distribution with the location parameter $x_{0}=0$ and the scale parameter $\gamma=0.5$ as suggested by Quintana \& Williams (Quintana and Williams 2018). The Bayes factor $\left(\mathrm{BF}_{01}\right)$ value $>1$ is interpreted as evidence for the null hypothesis, and $\mathrm{BF}_{01}>3$ refers to moderate evidence for the zero effect (Quintana and Williams 2018).

Statistical analyses were done using SAS for Windows version 9.4, SPSS version 24 and R software, and probability values below 0.05 were considered as statistically significant.

\section{Results}

\section{Attrition}

Of the 90 women included in the study, ten $(11.1 \%)$ dropped out during pregnancy. The attrition was higher in the control group $(18 \%, 8 / 44)$ compared to the intervention group $(4 \%, 2 / 46)(p=.047)$. Three women in the intervention group moved away from the hospital district during pregnancy. Differences were not found between the women who 
discontinued and those women who remained in the study regarding age, parity, marital status, educational level, substance abuse history, length of substance abuse, psychiatric morbidity, criminal acts, and previous children taken into custody. A flow chart regarding attrition is presented in Fig. 1.

Concerning the intervention group, $96 \%$ (44/46) of the participants attended the ultrasound sessions. Four percent $(2 / 46)$ of the participants in the intervention group attended one session, $17 \%(8 / 46)$ attended two sessions, and 74\% (34/46) attended all three sessions. Of those 12 women not attending all ultrasound sessions, four delivered prematurely, two withdrew from the study and six did not attend because of logistic reasons (moving to another hospital district or problems in scheduling by the research group). Further, $65 \%(30 / 46)$ of the participants in the intervention group attended the diary meetings: $20 \%(9 / 46)$ of the participants in the intervention group attended one meeting, 26.0\% (12/46) attended two meetings, and $20 \%$ (9/46) attended three meetings.

At baseline, the questionnaire response data was available for 96-98\% of the women in the intervention group and for $80 \%$ of the women in the control group. Post-intervention, the questionnaire data was available for $89 \%$ and $64 \%$ of the participants originally included in the groups, respectively. Only the validated 14-item version of P-PRFQ was used in the analysis at the post-intervention time point, so the P-PRFQ data was available in 59\% of the participants in the intervention group and in 55\% of the women initially allocated to the control group.

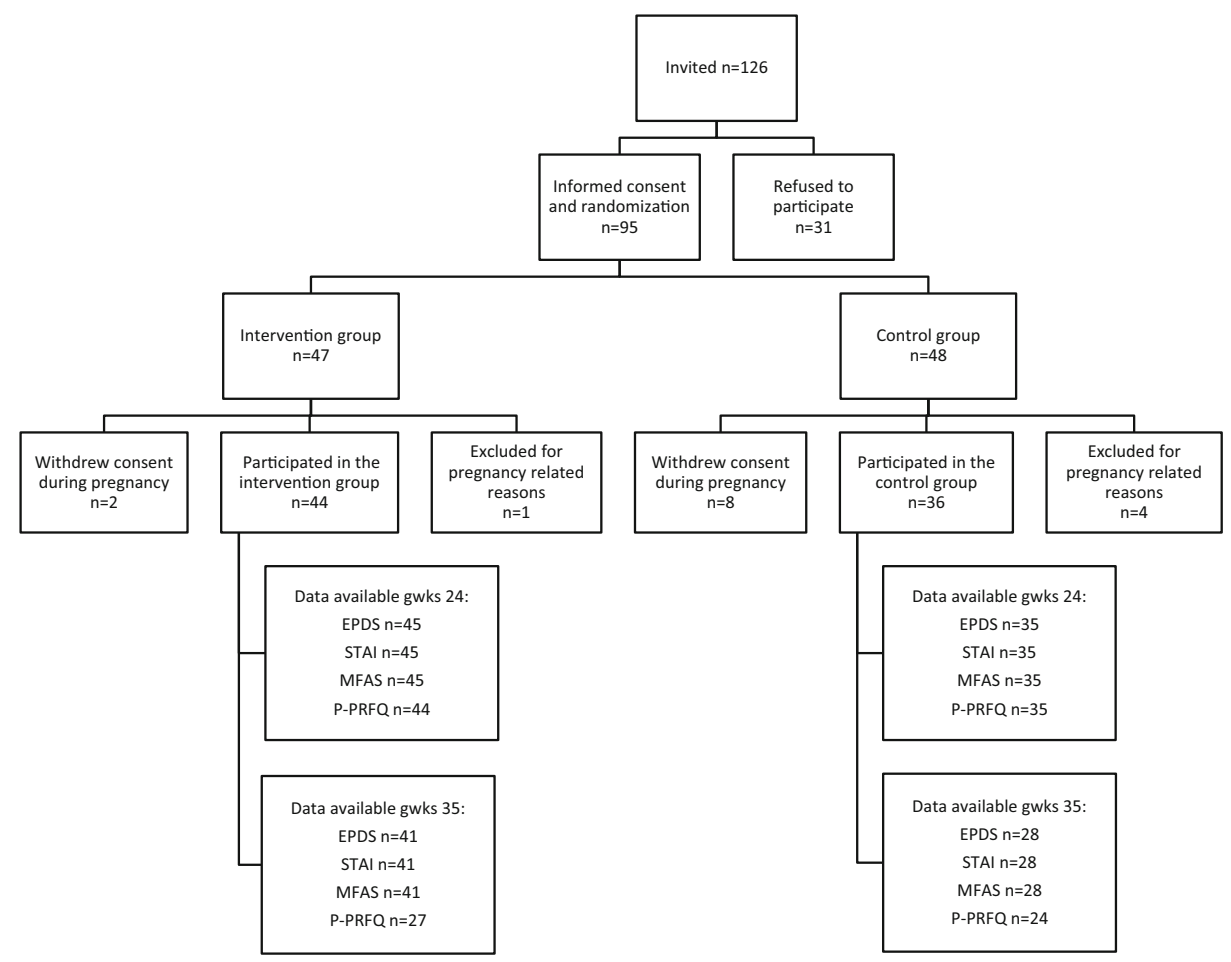

Fig. 1 Attrition flow chart (gwks = gestational weeks, EPDS = Edinburgh Pre/Postnatal Depression Scale, $\mathrm{STAI}=$ State-Trait Anxiety Inventory, MFAS = Maternal-fetal Attachment Scale, P-PRFQ = Prenatal Parental Reflective Functioning Questionnaire) 


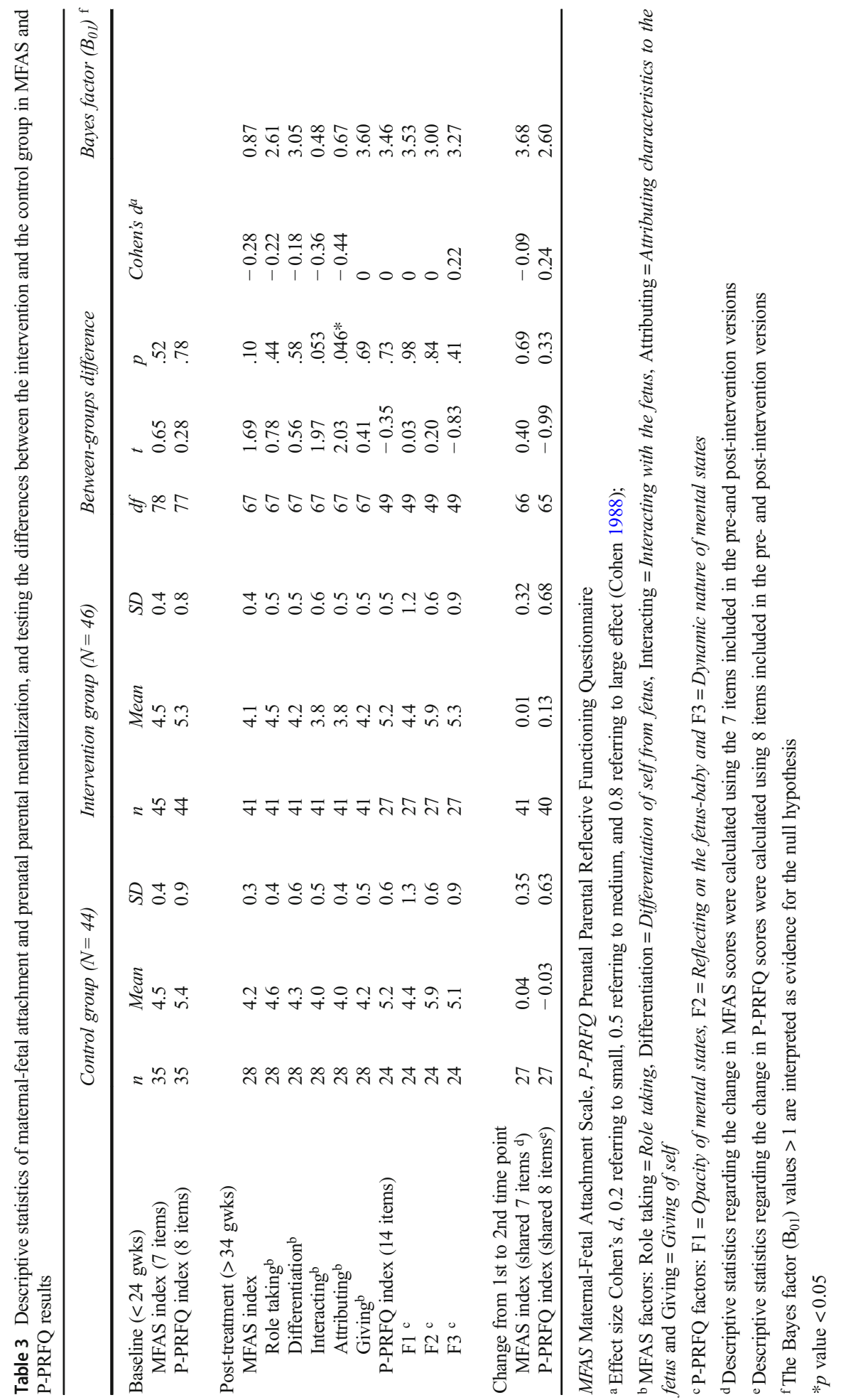




\section{The Efficacy of the Intervention on Prenatal Attachment and Mentalization}

Descriptive statistics and comparisons between the groups in maternal-fetal attachment (MFAS) and prenatal mentalization (P-PRFQ) are presented in Table 3. Both groups scored relatively high within the theoretical range of MFAS and P-PRFQ and the variation in the scores was small in the whole sample at both time points. Our hypothesis concerning the efficacy of the intervention on prenatal parental mentalization was not substantiated, as a difference between the groups as regards the level of parental mentalization was not displayed. The finding was inconclusive as to whether or not a difference between the groups in maternalfetal attachment was present post-intervention. Unexpectedly, the control group scored higher in the MFAS subscale "Attributing characteristics to the fetus" $\left(p=.046, \mathrm{BF}_{01}=0.67\right)$ postintervention.

\section{The Efficacy of the Intervention on the Change of Prenatal Attachment and Mentalization}

In the descriptive statistics concerning the change in prenatal parenting, the change in the PPRFQ scores was defined using the 8 items included in both the pre- and post-intervention versions of the measure. Similarly, the change in the MFAS scores was described using the seven items included in both the pre- and post-intervention versions. The descriptive statistics are presented in Table 3.

Analysis of covariance was used to determine whether there was a significant difference between the two groups in parental mentalization or maternal-fetal attachment after controlling for the baseline scores. Regarding parental mentalization, it should be noted that only the score of construct-validated 14-item version of P-PRFQ was used as a dependent variable in this analysis $(n=49)$. The findings were inconclusive as to whether or not a difference was present in prenatal parental mentalization $\left[F(1,46)=0.54, p=.47, \mathrm{BF}_{01}=2.85\right]$ or in maternal-fetal attachment $\left[F(1,65)=2.9, p=.09, \mathrm{BF}_{01}=1.13\right]$ after controlling for the baseline scores.

\section{The Efficacy of the Intervention on Prenatal Depressive and Anxiety Symptoms}

The effect of the intervention on prenatal depressive and anxiety symptoms is presented in Table 4. Within the whole sample, the prevalence of prenatal depression was $20 \%$ at the first time point and $8.7 \%$ at the second time point (EPDS sum $\geq 13$ ). Post-intervention, we did not find evidence for our hypotheses, as a difference between the groups as regards the level of depressive and anxiety symptoms or the cut-off prevalence of prenatal depression was not present.

\section{The Efficacy of the Intervention on the Change of Prenatal Depressive and Anxiety Symptoms}

Descriptive statistics regarding the change in prenatal anxiety and depressive symptoms are presented in Table 4. The level of depressive and anxiety symptoms declined in both the groups during pregnancy. A difference between the groups regarding the level of anxiety symptoms was not substantiated in the analysis of covariance after controlling for the baseline score [STAI: $F(1$, $\left.65)=0.003, p=.96, \mathrm{BF}_{01}=3.93\right]$. The finding was inconclusive as to whether or not a difference was present in prenatal depressive symptoms after adjusting for the baseline EPDS score [EPDS: $\left.F(1,65)=2.28, p=.14, \mathrm{BF}_{01}=1.54\right]$. 


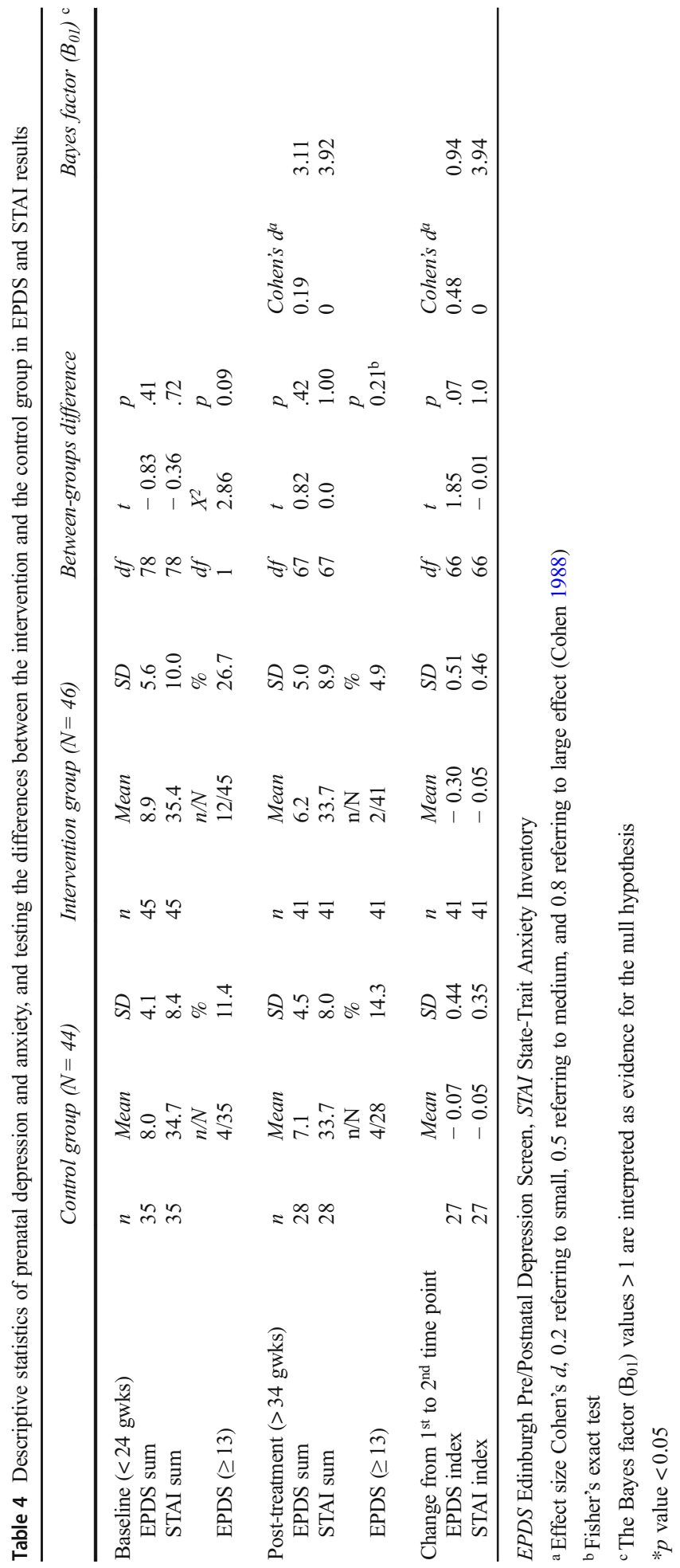




\section{Discussion}

In this paper, we report the preliminary results of testing the efficacy of a new prenatal mentalization-based ultrasound intervention for pregnant women with recent or current substance use. Unfortunately, the efficacy of the intervention on self-reported maternal prenatal mental health, maternal-fetal attachment and parental mentalization was not substantiated with the current sample and the research methods. The negative findings may be explained by the small sample size, the use of only self-report measures in the outcome assessment, or insufficient effect of the intervention on prenatal depression, anxiety, and parenting within this very high-risk group of pregnant women. It is of significance that as the relatively high retention rate suggests, the intervention approach was accepted well by the pregnant women with severe substance use problems.

Contrary to the hypothesis, we were not able to demonstrate evidence for the efficacy of the intervention on the self-reported maternal prenatal mental health, maternal-fetal attachment, and parental mentalization with the current sample and research methods. In some of our analyses, the results were inconclusive $\left(\mathrm{BF}_{01}\right.$ values within the range of $\left.0.33-3\right)$ and further research should be undertaken to evaluate the efficacy of the intervention with a larger sample. This is important, because the intervention may have a true beneficial effect on the outcomes, but our sample size may have been too small to detect small or moderate effects.

Our results suggest that the core mechanism of the intervention, enhancement in prenatal mentalization and attachment, was not substantiated. This finding may be explained by the difficulties of capturing the essence of prenatal parenting with the patient-reported outcome measures used. High-quality prenatal parenting is considered protective in the presence of antenatal adversities (Glover and Capron 2017) but, despite decades of research, the construct and assessment of maternal-fetal attachment is still being debated (McNamara et al. 2019). In the present study, maternal-fetal attachment was evaluated with one single self-report measure, which is known to capture primarily behavioral aspects of prenatal bonding (Cranley 1981; Brandon et al. 2009). The selfreport questionnaire used to assess prenatal parental mentalization (P-PRFQ) has recently been developed, but so far it has been validated and tested only within a low-risk sample (Pajulo et al. 2015). The P-PRFQ measure was still in the process of development during our data collection and, therefore, only about half of the participants responded to the construct-validated 14-item version of P-PRFQ. Our preliminary findings suggest that the P-PRFQ and the three subscales of the MFAS measure have low internal consistency in the sample of pregnant women with substance use problems (Cronbach's $\alpha<.60$ ). For these reasons, we may have not been able to completely capture the multidimensional and nuanced constructs of prenatal parental mentalization and attachment. Eventually, the intervention may have positively affected prenatal parenting, but we may not have been able to detect all possible benefits with the methodology used.

However, there is a complex balance between costs and benefits of self-reporting. In the present study, the self-report measures were used for feasibility reasons. First, the trial was conducted in the real-world clinical practice of prenatal obstetric care with limited resources to conduct extensive structural interviews or evaluation of mentalizing. Second, we did not want to burden these pregnant women with a demanding protocol and assessments that might even have constituted a barrier to prenatal visits. It is worth mentioning that pregnant women with substance use disorders perceive many barriers to prenatal care and the obstacles for treatment may also be related to practices in health care (Roberts and Pies 2011). 
Nevertheless, the lack of efficacy may result from the insufficient effect of the intervention on prenatal parenting and maternal mental health within this very high-risk group. There is a paucity of research investigating optimal mechanisms and means to alleviate prenatal depressive and anxiety symptoms. In the present study, the participants displayed multiple risk factors for perinatal mental disorders (Howard et al. 2014) and adversity in the transition to parenthood (Yarcheski et al. 2009; Alhusen 2008). The majority of the pregnancies were unintended, which is known to increase the risk for prenatal depression (Fellenzer and Cibula 2014). The pregnant mothers were often single parents or their partner had a substance use problem, suggesting insufficient psychosocial support and, thus, a burden for the mother's prenatal mental health and parenting (Howard et al. 2014; Alhusen et al. 2012a). Unfortunately, our results are in accord with previous studies addressing the great challenges encountered in the development, implementation, research, and efficacy of psychosocial interventions for pregnant women with substance use disorders. To our knowledge, the efficacy of psychosocial interventions on prenatal maternal mental health or parenting has not previously been explored with an RCT design among pregnant women with substance use problems (Howard et al. 2014; Terplan et al. 2015a; Glover and Capron 2017; Neger and Prinz 2015). Previous studies within this very high-risk group of pregnant women have also failed to show the efficacy of psychosocial interventions for treatment of substance use disorders on prenatal substance use, treatment retention, or obstetrical and neonatal outcomes (Terplan et al. 2015a).

Considering the high-risk profile of the sample, the participation and retention rates during pregnancy were rather high (Terplan et al. 2015a; Neger and Prinz 2015; Zedler et al. 2016). This was especially true for the patients' adherence to the ultrasound sessions, which was very good. We speculate that the concrete and interactive visualization of the fetus with a parenting focus may have been a particularly rewarding experience for these women and hence constitutes a meaningful encounter. One previous review on psychological effects of fetal ultrasound has shown ultrasound examinations to strengthen prenatal attachment and to increase the pregnant women's enthusiasm and positive emotions (de Jong-Pleij et al. 2013). The attendance at the diary meetings was not as high. Reflecting experiences evoked by the diary may have been challenging for these women who often have specific difficulties in expressing themselves verbally (Pajulo et al. 2012) and in achieving sufficient insight (Goldstein et al. 2009) and level of self-mentalization (Suchman et al. 2010). The relatively low attendance rate at the diary visits may have decreased the efficacy of the intervention. It should be noted, however, that the pregnancy diary was designed and implemented with the basic idea that it would have a positive effect on prenatal parenting independently by inspiring the mothers' parental mentalization while using it at home. Precisely how much or how regularly each of them used it, was not assessed. In the control group, those pregnant women who discontinued did so immediately after randomization when they were allocated to the group not receiving the intervention. Importantly, the difference in attrition may suggest the potential of the intervention approach, especially mentalization-based interactive ultrasound sessions, to attract these high-risk pregnant women. However, the difference in attrition also diminishes the experimental validity of the study. Nonetheless, the higher attrition in the control group (attrition bias) may have had some influence on the balance of confounding factors among the study groups. We speculate that the most disadvantaged patients may have remained in the intervention group because of their interest in the intervention. 
On average, the participants self-reported surprisingly low levels of prenatal depressive and anxiety symptoms considering their high-risk situation and the accumulation of severe risks for prenatal mental disorders (Fellenzer and Cibula 2014; Lancaster et al. 2010). The prevalence of prenatal depression was smaller at both time points compared to previous studies with similar samples (Holbrook and Kaltenbach 2012; Ordean et al. 2013). Compared to results from a population-based birth cohort in Finland (Tolvanen et al. 2013), the participants in the current study only reported slightly higher levels of prenatal anxiety and depressive symptoms, and mostly in the earlier phase of pregnancy. Considering the background of these mothers, the levels of self-reported maternal-fetal attachment and prenatal mentalization were found to be surprisingly high in both groups. Prenatal attachment has normally been found to strengthen during pregnancy (Yarcheski et al. 2009). It is of note that this dynamic profile in maternalfetal attachment was not evident among the mothers of the present study. Instead, the rather high self-reported level of prenatal bonding stayed about the same across pregnancy. With respect to our findings, previous observations regarding the level of prenatal attachment among disadvantaged women have varied (Magee et al. 2014; Massey et al. 2015; Alhusen et al. 2012b). The participants in the current study scored slightly higher in prenatal attachment than the pregnant women in the one previous study using the MFAS measure on a sample of women with illicit drug use (Shieh and Kravitz 2006). More unexpectedly, the high-risk patients in the present study reported a higher level of prenatal mentalization than the participants in the recent population-based birth cohort in the same geographical area (Pajulo et al. 2015), which is discordant with earlier findings from studies evaluating parental mentalization with interview methods (Pajulo et al. 2008; Pajulo et al. 2012; Suchman et al. 2010; Suchman et al. 2017).

The relatively low level of prenatal depressive and anxiety symptoms and the highly positive prenatal parenting reported by the participants may partly be attributed to good access to prenatal care. Indeed, high access to care has been found to improve the prenatal health of disadvantaged or substance using pregnant women (Aizer and Currie 2014; Kotelchuck et al. 2017). Further, being part of a randomized and controlled trial may have had a favorable effect per se (Nijjar et al. 2017). However, this finding may also be related to a social desirability bias and other problems in self-reporting within the sample of pregnant women with substance use problems. The patients were asked to report depressive and anxiety symptoms and evaluate their parenting in the context of public health care which includes the known involvement of Child Welfare Services. The pregnant women gave the questionnaires personally, although in a closed envelope, to the hospital social worker collaborating with Child Welfare authorities. Awareness of this combined with fear of losing custody of the child may have affected the mothers' way of responding, i.e. a tendency to give a more positive picture of their situation (Roberts and Pies 2011; Terplan et al. 2015b). The overall answering pattern of the participants may also reflect unbalanced and idealized prenatal representations, which have been observed in high-risk parents, and among substance using pregnant women in particular (Flykt et al. 2012). Specifically, the participants' idealizing tendency in prenatal representations should be recognized as a risk factor for the early interaction and the relationship between the mother and the infant (Flykt et al. 2012). Self-reporting of symptoms or quality of parenting may also be particularly problematic in this group for other reasons. Parental mentalization (Pajulo et al. 2008; Pajulo et al. 2012; Suchman et al. 2010; Suchman et al. 2017), self-mentalization (Suchman et al. 2010) as well as insight (Goldstein et al. 2009) have been found, on average, to be weak among persons suffering from substance use disorders. This may be manifested as a weaker capacity to recognize and self-report difficulties and/or mental states. 


\section{Strengths and Limitations}

The rather small sample size and the use of only self-reports in the outcome assessment within the high-risk sample and the context of Child Welfare follow-up are significant limitations in the present study. The control group received comprehensive treatmentas-usual, provided by the multidisciplinary treatment team, in the obstetric tertiary unit. The usual treatment also included psychosocial support for the mother and, in addition, a majority of the participants were also involved in other treatment modalities that integrate addiction and mental health treatment and support for the transition to parenthood. In this real-world setting, the content of treatment-as-usual has been individually tailored and diverse. Further, the intervention included two major components, and the contribution of each of them was not explored separately, which is a limitation.

The present study was, however, pioneer work in many aspects. The intervention included new ideas and routes for intervening. The efficacy of the intervention was explored in a realworld clinical practice within a public health care setting using an RCT design. The intervention development and implementation was a genuine effort towards more integrated prenatal care, and aimed to enhance collaboration between expertise from obstetrics, pediatrics, psychiatry, addiction medicine, and infant mental health work. A novel measure was used and tested in the assessment of prenatal parental mentalization. This is important, as attempts to develop feasible measures for assessment of different aspects of prenatal parenting in large, diverse or clinical samples are greatly needed.

\section{Future Directions and Conclusions}

This study emphasizes the lessons learned from conducting an RCT study among a high-risk sample of pregnant women with recent or current substance use in a real-world setting. The efficacy of the intervention should be evaluated with a larger sample and more objective methods, based on video-observation and structured clinical and method interviews. Investing more attention and structuring to enhance the mothers' prenatal mentalization during the 4D sessions, collecting maternal feedback and experience more systematically, and including videotaped session in the study will be important in developing the intervention further (Pajulo et al. 2016).

Our findings were negative or inconclusive as to whether or not prenatal maternal mental health, attachment and parental mentalization improved in response to the intervention. We consider that the intervention approach has a better potential to positively affect prenatal parenting and maternal mental health than we were able to capture with the methodology used. A parental mentalization focus combined with interactive 4D ultrasound imaging offers a novel route to strengthening the reward that can be gained from parenting in pregnancy and to potentially alleviating prenatal stress. This is particularly important among pregnant women with substance use disorders since their neural circuitries, which are essential in stress regulation and pleasure of caregiving, are likely to be dysregulated by addiction (Rutherford and Mayes 2017). The rather good retention in the study should be positively acknowledged. The interest and acceptance shown by these high-risk pregnant women is an encouragement to the further development of the intervention. 
Acknowledgments We would like to express our deep gratitude to all the participants and the hospital personnel carrying out this study with special thanks to professor Jorma Piha, psychotherapist Outi Kallioinen, and statisticians Juho Pelto and Jaakko Matomäki. The investigators would like to acknowledge The Finnish Pediatric Research Foundation, The Hospital District of Southwest Finland, Academy of Finland, and University of Turku for funding for this research.

Funding Information Open access funding provided by University of Turku (UTU) including Turku University Central Hospital. This study was funded by The Finnish Pediatric Research Foundation (MP, EE), The Hospital District of Southwest Finland (MP, EE), Academy of Finland (MP), and University of Turku (HJ).

\section{Compliance with Ethical Standards}

All procedures followed were in accordance with the ethical standards of the responsible committee on human experimentation and with the Helsinki Declaration of 1964, and its later amendments. The study was approved by the Joint Ethics Committee of the University of Turku and The Hospital District of Southwest Finland on 14th of June 2011. The trial was registered retrospectively in the ClinicalTrials.gov (the reference number: NCT03413631). Informed consent was obtained from all individual participants included in the study.

Conflict of Interest The authors declare that they have no conflict of interest.

Ethical Approval All procedures performed in studies involving human participants were in accordance with the ethical standards of the institutional research committee on human experimentation and with the Helsinki Declaration of 1964, and its later amendments.

Open Access This article is licensed under a Creative Commons Attribution 4.0 International License, which permits use, sharing, adaptation, distribution and reproduction in any medium or format, as long as you give appropriate credit to the original author(s) and the source, provide a link to the Creative Commons licence, and indicate if changes were made. The images or other third party material in this article are included in the article's Creative Commons licence, unless indicated otherwise in a credit line to the material. If material is not included in the article's Creative Commons licence and your intended use is not permitted by statutory regulation or exceeds the permitted use, you will need to obtain permission directly from the copyright holder. To view a copy of this licence, visit http://creativecommons.org/licenses/by/4.0/.

\section{References}

Aizer, A., \& Currie, J. (2014). The intergenerational transmission of inequality: Maternal disadvantage and health at birth. Science, 344(6186), 856-861.

Alhusen, J. L. (2008). A literature update on maternal-fetal attachment. Journal of Obstetric, Gynecologic, and Neonatal Nursing, 37(3), 315-328.

Alhusen, J. L., Gross, D., Hayat, M. J., Rose, L., \& Sharps, P. (2012a). The role of mental health on maternalfetal attachment in low-income women. Journal of Obstetric, Gynecologic, and Neonatal Nursing, 41(6), E71-E81.

Alhusen, J. L., Gross, D., Hayat, M. J., Woods, A. B., \& Sharps, P. W. (2012b). The influence of maternal-fetal attachment and health practices on neonatal outcomes in low-income, urban women. Research in Nursing \& Health, 35(2), 112-120.

Alhusen, J. L., Hayat, M. J., \& Gross, D. (2013). A longitudinal study of maternal attachment and infant developmental outcomes. Archives of Women's Mental Health, 16(6), 521-529.

Alhusen, J., Ayres, L., \& DePriest, K. (2016). Effects of maternal mental health on engagement in favorable health practices during pregnancy. Journal of Midwifery \& Women's Health, 61(2), 210-216.

Bada, H. S., Bann, C. M., Whitaker, T. M., Bauer, C. R., Shankaran, S., Lagasse, L., et al. (2012). Protective factors can mitigate behavior problems after prenatal cocaine and other drug exposures. Pediatrics, 130(6), e1479-e1488.

Behnke, M., \& Smith, V. C. (2013). Committee on substance Abuse, committee on fetus and newborn. Prenatal substance abuse: Short- and long-term effects on the exposed fetus. Pediatrics, 131(3), e1009-e1024. 
Berthelot, N., Lemieux, R., Garon Bissonnette, J., Lacharité, C., \& Muzik, M. (2019). The protective role of mentalizing: Reflective functioning as a mediator between child maltreatment, psychopathology and parental attitude in expecting parents. Child Abuse \& Neglect, 95, 104065-104065.

Borg Cunen, N., Jomeen, J., Borg Xuereb, R., \& Poat, A. (2017). A narrative review of interventions addressing the parental-fetal relationship. Women and Birth, 30(4), e141-e151.

Boukydis, Z. (2006). Ultrasound consultation to reduce risk and increase resilience in pregnancy. Annals of the New York Academy of Sciences, 1094, 268-271.

Boukydis, Z., \& Stockman, A. (2012). Watching babies in pregnancy: The ultrasound consultation. In Z. Boukydis (Ed.), Collaborative consultation with parents and infants in the perinatal period (pp. 131157). Baltimore: Paul H. Brookes Publisihing Co., Inc..

Boukydis, C. F., Treadwell, M. C., Delaney-Black, V., Boyes, K., King, M., Robinson, T., \& Sokol, R. (2006). Women's responses to ultrasound examinations during routine screens in an obstetric clinic. Journal of Ultrasound in Medicine, 25(6), 721-728.

Brandon, A. R., Pitts, S., Denton, W. H., Stringer, C. A., \& Evans, H. M. (2009). A history of the theory of prenatal attachment. The Journal of Prenatal and Perinatal Psychology and Health, 23(4), 201-222.

Britto, P., Lye, S., Proulx, K., Yousafzai, A., Matthews, S., Vaivada, T., Perez-Escamilla, R., Rao, N., Ip, P., Fernald, L. C. H., MacMillan, H., Hanson, M., Wachs, T. D., Yao, H., Yoshikawa, H., Cerezo, A., Leckman, J. F., Bhutta, Z. A., \& Early Childhood Development Interventions Review Group, for the Lancet Early Childhood Development Series Steering Committee. (2017). Nurturing care: Promoting early childhood development. Lancet, 389(10064), 91-102.

Camoirano, A. (2017). Mentalizing makes parenting work: A review about parental reflective functioning and clinical interventions to improve it. Frontiers in Psychology, 8, 14.

Cannella, B. (2005). Maternal-fetal attachment: An integrative review. Journal of Advanced Nursing, 50(1), 6068.

Cannella, B., Yarcheski, A., \& Mahon, N. (2018). Meta-analyses of predictors of health practices in pregnant women. Western Journal of Nursing Research, 40(3), 425-446.

Cohen, J. (1988). Statistical power analysis for the behavioral sciences (2nd ed.). Hillsdale: Lawrence Erlbaum.

Cox, J. L., Holden, J. M., \& Sagovsky, R. (1987). Detection of postnatal depression. Development of the 10-item Edinburgh postnatal depression scale. British Journal of Psychiatry, 150, 782-786.

Cranley, M. S. (1981). Development of a tool for the measurement of maternal attachment during pregnancy. Nursing Research, 30(5), 281-284.

de Jong-Pleij, E. A., Ribbert, L. S., Pistorius, L. R., Tromp, E., Mulder, E. J., \& Bilardo, C. M. (2013). Threedimensional ultrasound and maternal bonding, a third trimester study and a review. Prenatal Diagnosis, 33(1), 81-88.

Desai, R., Huybrechts, K., Hernandez Diaz, S., Mogun, H., Patorno, E., Kaltenbach, K., et al. (2015). Exposure to prescription opioid analgesics in utero and risk of neonatal abstinence syndrome: Population based cohort study. BMJ, 350, h2102-h2102.

Dubber, S., Reck, C., Muller, M., \& Gawlik, S. (2015). Postpartum bonding: The role of perinatal depression, anxiety and maternal-fetal bonding during pregnancy. Archives of Women's Mental Health, 18(2), 187-195.

Fellenzer, J., \& Cibula, D. (2014). Intendedness of pregnancy and other predictive factors for symptoms of prenatal depression in a population-based study. Maternal and Child Health Journal, 18(10), 2426-2436.

Flykt, M., Punamäki, R., Belt, R., Biringen, Z., Salo, S., Posa, T., \& Pajulo, M. (2012). Maternal representations and emotional availability among drug-abusing and nonusing mothers and their infants. Infant Mental Health Journal, 33(2), 123-138.

Foley, S. (2018). Great expectations? Do mothers' and fathers' prenatal thoughts and feelings about the infant predict parent-infant interaction quality? A meta-analytic review. Developmental Review, 48, 40-54.

Forray, A., \& Foster, D. (2015). Substance use in the perinatal period. Current Psychiatry Reports, 17(11), 91 015-0626-5.

Forray, A., Gotman, N., Kershaw, T., \& Yonkers, K. A. (2014). Perinatal smoking and depression in women with concurrent substance use. Addictive Behaviors, 39(4), 749-756.

Gavin, N. I., Gaynes, B. N., Lohr, K. N., Meltzer-Brody, S., Gartlehner, G., \& Swinson, T. (2005). Perinatal depression: A systematic review of prevalence and incidence. Obstetrics and Gynecology, 106(5 Pt 1), 1071-1083.

Glover, V., \& Capron, L. (2017 Jun). Prenatal parenting. Current Opinion in Psychology, 15, 66-70.

Goecke, T. W., Voigt, F., Faschingbauer, F., Spangler, G., Beckmann, M. W., \& Beetz, A. (2012). The association of prenatal attachment and perinatal factors with pre- and postpartum depression in first-time mothers. Archives of Gynecology and Obstetrics, 286(2), 309-316.

Goldstein, R. Z., Craig, A. D., Bechara, A., Garavan, H., Childress, A. R., Paulus, M. P., \& Volkow, N. D. (2009). The neurocircuitry of impaired insight in drug addiction. Trends in Cognitive Sciences, 13(9), 372380 . 
Grant, K. A., McMahon, C., \& Austin, M. P. (2008). Maternal anxiety during the transition to parenthood: A prospective study. Journal of Affective Disorders, 108(1-2), 101-111.

Holbrook, A., \& Kaltenbach, K. (2012 Nov). Co-occurring psychiatric symptoms in opioid-dependent women: The prevalence of antenatal and postnatal depression. The American Journal of Drug and Alcohol Abuse, 38(6), 575-579.

Howard, L. M., Molyneaux, E., Dennis, C. L., Rochat, T., Stein, A., \& Milgrom, J. (2014). Non-psychotic mental disorders in the perinatal period. Lancet, 384(9956), 1775-1788.

Huth Bocks, A., Levendosky, A., Bogat, G. A., \& von Eye, A. (2004). The impact of maternal characteristics and contextual variables on infant-mother attachment. Child Development, 75(2), 480-496.

Hyer J, Ulrickson C, Yerelian E, Metz T, Allshouse A, Hoffman MC. Self-Reported Alcohol, Tobacco, and Marijuana Use in Pregnant Women with Depressive Symptomatology. American Journal of Perinatology 2019.

Jessup, M. A., Ross, T. B., Jones, A. L., Satre, D. D., Weisner, C. M., Chi, F. W., \& Mertens, J. R. (2014). Significant life events and their impact on alcohol and drug use: A qualitative study. Journal of Psychoactive Drugs, 46(5), 450-459.

Kokkevi, A., \& Hartgers, C. (1995). EuropASI: European adaptation of a multidimensional assessment instrument for drug and alcohol dependence. European Addiction Research, 1, 208-210.

Kotelchuck, M., Cheng, E. R., Belanoff, C., Cabral, H. J., Babakhanlou-Chase, H., Derrington, T. M., et al. (2017). The prevalence and impact of substance use disorder and treatment on maternal obstetric experiences and birth outcomes among singleton deliveries in Massachusetts. Maternal and Child Health Journal, 21(4), 893-902.

Kozinszky, Z., \& Dudas, R. B. (2015). Validation studies of the Edinburgh postnatal depression scale for the antenatal period. Journal of Affective Disorders, 176, 95-105.

Lancaster, C., Gold, K., Flynn, H., Yoo, H., Marcus, S., \& Davis, M. (2010). Risk factors for depressive symptoms during pregnancy: A systematic review. American Journal of Obstetrics and Gynecology, 202(1), $5-14$.

Luyten, P., Mayes, L., Sadler, L., Fonagy, P., Nicholls, S., Crowley, M. J., et al. (2009). The parental reflective functioning questionnaire - 1 (PRFQ-1). New Haven: Manual. Yale Child Study Center.

MacLean, R. R., Armstrong, J., \& Sofuoglu, M. (2019). Stress and opioid use disorder: A systematic review. Addictive Behaviors, 98, 106010-106010.

Magee, S. R., Bublitz, M. H., Orazine, C., Brush, B., Salisbury, A., Niaura, R., \& Stroud, L. R. (2014). The relationship between maternal-fetal attachment and cigarette smoking over pregnancy. Maternal and Child Health Journal, 18(4), 1017-1022.

Massey, S., Bublitz, M., Magee, S., Salisbury, A., Niaura, R., Wakschlag, L., \& Stroud, L. R. (2015). Maternalfetal attachment differentiates patterns of prenatal smoking and exposure. Addictive Behaviors, 45, 51-56.

McNamara, J., Townsend, M., \& Herbert, J. (2019). A systemic review of maternal wellbeing and its relationship with maternal fetal attachment and early postpartum bonding. PLoS One, 14(7), e 0220032-e0220032.

Morey R, Rouder J, Jamil T. BayesFactor: Computation of Bayes Factors for common designs.R package version 0.9.12-4.2 2018 .

Neger, E. N., \& Prinz, R. J. (2015). Interventions to address parenting and parental substance abuse: Conceptual and methodological considerations. Clinical Psychology Review, 39, 71-82.

Nijjar, S. K., D'Amico, M. I., Wimalaweera, N. A., Cooper, N., Zamora, J., \& Khan, K. S. (2017). Participation in clinical trials improves outcomes in women's health: A systematic review and meta-analysis. BJOG, 124(6), 863-871.

Ollgren, J., Forsell, M., Varjonen, V., Alho, H., Brummer-Korvenkontio, H., Kainulainen, H., et al. (2014). Amfetamiinien ja opioidien ongelmakäytön yleisyys Suomessa 2012 (Prevalence of amphetamine and opioid abuse in Finland 2012). Yhteiskuntapolitiikka, 79(5), 513-523.

Ordean, A., Kahan, M., Graves, L., Abrahams, R., \& Boyajian, T. (2013). Integrated care for pregnant women on methadone maintenance treatment: Canadian primary care cohort study. Canadian Family Physician, 59(10), e462-e469.

Pajulo, M., Suchman, N., Kalland, M., Sinkkonen, J., Helenius, H., \& Mayes, L. (2008). Role of maternal reflective ability for substance abusing mothers. The Journal of Prenatal and Perinatal Psychology and Health, 23(1), 13-31.

Pajulo, M., Pyykkonen, N., Kalland, M., Sinkkonen, J., Helenius, H., \& Punamaki, R. L. (2011a). Substance abusing mothers in residential treatment with their babies: Postnatal psychiatric symptomatology and its association with mother-child relationship and later need for child protection actions. Nordic Journal of Psychiatry, 65(1), 65-73.

Pajulo, M., Ekholm, E., Kallioinen, O., Kortekangas, L., Von Koskull, M., \& Andersson, G. (2011b). Vauva mielessä - raskauspäiväkirja odottavalle äidille. (the baby in mind - A new RF focused pregnancy diary). Helsinki: Folkhälsans förbund. 
Pajulo, M., Pyykkonen, N., Kalland, M., Sinkkonen, J., Helenius, H., Punamaki, R. L., et al. (2012). Substanceabusing mothers in residential treatment with their babies: Importance of pre- and postnatal maternal reflective functioning. Infant Mental Health Journal, 33(1), 70-81.

Pajulo, M., Tolvanen, M., Karlsson, L., Halme-Chowdhury, E., Ost, C., Luyten, P., et al. (2015). The prenatal parental reflective functioning questionnaire: Exploring factor structure and construct validity of a new measure in the Finn brain birth cohort pilot study. Infant Mental Health Journal, 36(4), 399-414.

Pajulo, H., Pajulo, M., Jussila, H., \& Ekholm, E. (2016). Substance-abusing pregnant women: Prenatal intervention using ultrasound consultation and mentalization to enhance the mother-child relationship and reduce substance use. Infant Mental Health Journal, 37(4), 317-334.

Parolin, M., \& Simonelli, A. (2016). Attachment theory and maternal drug addiction: The contribution to parenting interventions. Frontiers in Psychiatry, 7, 152.

Patrick, S. W., Dudley, J., Martin, P. R., Harrell, F. E., Warren, M. D., Hartmann, K. E., et al. (2015). Prescription opioid epidemic and infant outcomes. Pediatrics, 135(5), 842-850.

Quintana, D., \& Williams, D. (2018). Bayesian alternatives for common null-hypothesis significance tests in psychiatry: A non-technical guide using JASP. BMC Psychiatry, 18(1), 178-178.

Roberts, S. C. M., \& Pies, C. (2011). Complex calculations: How drug use during pregnancy becomes a barrier to prenatal care. Maternal and Child Health Journal, 15(3), 333-341.

Roozen, S., Peters, G. J., Kok, G., Townend, D., Nijhuis, J., \& Curfs, L. (2016). Worldwide prevalence of fetal alcohol Spectrum disorders: A systematic literature review including meta-analysis. Alcoholism, Clinical and Experimental Research, 40(1), 18-32.

Rubertsson, C., Borjesson, K., Berglund, A., Josefsson, A., \& Sydsjo, G. (2011). The Swedish validation of Edinburgh postnatal depression scale (EPDS) during pregnancy. Nordic Journal of Psychiatry, 65(6), 414-418.

Russell, M. (1994). New risk assessment tools for risk drinking during pregnancy. T-ACE, TWEAK, and others. Alcohol Health \& Research World, 1, 55-61.

Rutherford, H. J., \& Mayes, L. C. (2017 Jun). Parenting and addiction: Neurobiological insights. Current Opinion in Psychology, 15, 55-60.

Rutherford, H., \& Mayes, L. (2019). Parenting stress: A novel mechanism of addiction vulnerability. Neurobiol Stress, 11, 100172-100172.

Sedgmen, B., McMahon, C., Cairns, D., Benzie, R. J., \& Woodfield, R. L. (2006). The impact of twodimensional versus three-dimensional ultrasound exposure on maternal-fetal attachment and maternal health behavior in pregnancy. Ultrasound in Obstetrics \& Gynecology, 27(3), 245-251.

Shieh, C., \& Kravitz, M. (2002). Maternal-fetal attachment in pregnant women who use illicit drugs. Journal of Obstetric, Gynecologic, and Neonatal Nursing, 31(2), 156-164.

Shieh, C., \& Kravitz, M. (2006). Severity of drug use, initiation of prenatal care, and maternal-fetal attachment in pregnant marijuana and cocaine/heroin users. Journal of Obstetric, Gynecologic, and Neonatal Nursing, 35(4), 499-508.

Shmulewitz, D., \& Hasin, D. (2019). Risk factors for alcohol use among pregnant women, ages $15-44$, in the United States, 2002 to 2017. Preventive Medicine, 124, 75-83.

Siddiqui, A., \& Hagglof, B. (2000). Does maternal prenatal attachment predict postnatal mother-infant interaction? Early Human Development, 59(1), 13-25.

Slade, A. (2005). Parental reflective functioning: An introduction. Attachment \& Human Development, 7(3), 269-281.

Slade A, Patterson M, Miller M. Addendum to Reflective Functioning Scoring Manual (Fonagy, Steele, Steele, Target 1998). For use with the Pregnancy Interview (Slade Grunebaum, Huganir,\& Reeves 1987; Slade 2004). : The City College and Graduate Center of the City University of New York; 2007.

Spielberger, C. D., Gorsuch, R. L., \& Lushene, R. E. (1970). STAI manual for the state-trait anxiety inventory ("self-evaluation questionnaire"). Palo Alto: Consulting Psychologists Press.

Stein, A., Pearson, R. M., Goodman, S. H., Rapa, E., Rahman, A., McCallum, M., Howard, L. M., \& Pariante, C. M. (2014). Effects of perinatal mental disorders on the fetus and child. Lancet, 384(9956), 1800-1819.

Strengell, P., Vaisanen, I., Joukamaa, M., Luukkaala, T., \& Seppa, K. (2014). Psychiatric comorbidity among substance misusing mothers. Nordic Journal of Psychiatry, 26, 1-7.

Substance Abuse and Mental Health Services Administration. Results from the 2013 National Survey on Drug Use and Health: Summary of National Findings. 2014;NSDUH Series H-48, HHS Publication No. (SMA) $14-4863$.

Suchman, N. E., DeCoste, C., Leigh, D., \& Borelli, J. (2010). Reflective functioning in mothers with drug use disorders: Implications for dyadic interactions with infants and toddlers. Attachment \& Human Development, 12(6), 567-585.

Suchman, N., Pajulo, M., Kalland, M., Decoste, C., \& Mayes, L. (2011). At-risk mothers of infants and toddlers. In A. Bateman \& P. Fonagy (Eds.), Handbook of Mentalizing in mental health practice (pp. 309-346). Washington: American Psychiatric Publishing Inc.. 
Suchman, N., DeCoste, C., McMahon, T., Dalton, R., Mayes, L., \& Borelli, J. (2017). Mothering from the inside out: Results of a second randomized clinical trial testing a mentalization-based intervention for mothers in addiction treatment. Development and Psychopathology, 29(2), 617-636.

Suchman, N., DeCoste, C., Borelli, J., \& McMahon, T. (2018). Does improvement in maternal attachment representations predict greater maternal sensitivity, child attachment security and lower rates of relapse to substance use? A second test of mothering from the inside out treatment mechanisms. Journal of Substance Abuse Treatment, 85, 21-30.

Terplan M, Ramanadhan S, Locke A, Longinaker N, Lui S. Psychosocial interventions for pregnant women in outpatient illicit drug treatment programs compared to other interventions. Cochrane Database of Systematic Reviews 2015a(Issue 4, Art. No.: CD006037).

Terplan, M., Kennedy Hendricks, A., \& Chisolm, M. (2015b). Prenatal substance use: Exploring assumptions of maternal unfitness. Substance Abuse, 9(Suppl 2), 1-4.

Tolvanen, M., Hagqvist, O., Luoto, A., Rantavuori, K., Karlsson, L., Karlsson, H., et al. (2013). Changes over time in adult dental fear and correlation to depression and anxiety: A cohort study of pregnant mothers and fathers. European Journal of Oral Sciences, 121(3), 264-269.

Traub F, Boynton Jarrett R. Modifiable Resilience Factors to Childhood Adversity for Clinical Pediatric Practice. Pediatrics 2017;139(5).

Waters, C. S., Hay, D. F., Simmonds, J. R., \& van Goozen, S. H. (2014). Antenatal depression and children's developmental outcomes: Potential mechanisms and treatment options. European Child \& Adolescent Psychiatry, 23(10), 957-971.

Webpages of National Institute for Health and Welfare in Finland. Children, young people and families: Promoting the well-being of children. (cited 28.11.2016). 2015; Available at: https://www.thl. fi/fi/web/lapset-nuoret-ja-perheet/peruspalvelut/aitiys_ja_lastenneuvola/aitiysneuvola. Accessed 11/28, 2016.

Wlodarczyk, O., Schwarze, M., Rumpf, H. J., Metzner, F., \& Pawils, S. (2017). Protective mental health factors in children of parents with alcohol and drug use disorders: A systematic review. PLoS One, 12(6), e0179140.

Woods, S. M., Melville, J. L., Guo, Y., Fan, M. Y., \& Gavin, A. (2010). Psychosocial stress during pregnancy. American Journal of Obstetrics and Gynecology, 202(1), 61.e1-61.e7.

Yarcheski, A., Mahon, N. E., Yarcheski, T. J., Hanks, M. M., \& Cannella, B. L. (2009). A meta-analytic study of predictors of maternal-fetal attachment. International Journal of Nursing Studies, 46(5), 708-715.

Zedler, B., Mann, A., Kim, M., Amick, H., Joyce, A., Murrelle, E. L., \& Jones, H. E. (2016). Buprenorphine compared with methadone to treat pregnant women with opioid use disorder: A systematic review and metaanalysis of safety in the mother, fetus and child. Addiction, 111(12), 2115-2128.

Zhao, L., McCauley, K., \& Sheeran, L. (2017). The interaction of pregnancy, substance use and mental illness on birthing outcomes in Australia. Midwifery, 54, 81-88.

Publisher's Note Springer Nature remains neutral with regard to jurisdictional claims in published maps and institutional affiliations.

\section{Affiliations}

\section{Heidi Jussila ${ }^{1,2} \cdot$ Eeva Ekholm $^{3,4} \cdot$ Marjukka Pajulo $^{5}$}

1 Doctoral Programme of Clinical Investigation, Department of Child Psychiatry, University of Turku, 20014 Turku, Finland

2 Department of Child Psychiatry, Turku University Hospital, Kiinamyllynkatu 4-8, PL 52, 20521 Turku, Finland

3 Department of Obstetrics and Gynecology, Turku University Hospital, Kiinamyllynkatu 4-8, PL 52, 20521 Turku, Finland

4 Department of Obstetrics and Gynecology, University of Turku, 20014 Turku, Finland

5 Department of Child Psychiatry and The Finn Brain Cohort Study, Institute of Clinical Medicine, University of Turku, 20014 Turku, Finland 